\title{
On Preferred Zonal Scale of Wave-CISK with Conditional Heating
}

\author{
By Shang-Ping Xie ${ }^{1}$ \\ Program in Atmospheric and Oceanic Sciences, Princeton University, Princeton, NJ08544, U.S.A. \\ (Manuscript received 19 April 1993, in revised form 5 November 1993)
}

\begin{abstract}
Wave-CISK (conditional instability of second kind) with conditional heating on a rotating sphere is investigated using a global spectral model. With certain initial conditions, an eastward-propagating wavenumber-one mode with a single ascending region is obtained. With more general initial conditions, however, more than one convection events, of nearly equal strength and separated at nearly equal intervals, coxist and interact very little with each other. This happens when the radius for a convection event to affect other such events, which is inversely proportional to the growth rate, is much smaller than the circumference of the earth. In additional to the eastward propagating modes, a westwardpropagating mode is also found, whose flow field is dominated by gravity wave response to the cumulus heating.

The above results indicate that the wave-CISK with conditional heating does not always select the eastward-propagating wavenumber-one mode. An alternative mechanism that leads to the selectivity of the wavenumber-one mode is suggested.
\end{abstract}

\section{Introduction}

The intraseasonal oscillations $(I S O)$ with a typical time scale of 30 to 60 days are a dominant mode of the low-frequency atmospheric variability in the tropics. The observation indicates that the ISO is a result of the organizing of tropical convection on the planetary scale (Madden and Julian, 1972). This notion is supported by recent GCM (general circulation mode) experiments under realistic boundary condition (Lau and Lau, 1986; Hayashi and Golder, $1986,1988)$ and idealized, so-called aqua-planet conditions (Hayashi and Sumi, 1986; Swinbank et al., 1987; Lau et al., 1988; Tokioka et al., 1988). Although each of the above GCMs is started with different initial conditions and the behavior of mesoscale convection differs from one model to the other, the eastward-moving, wavenumber-one mode is a common and robust feature in these models. The interaction between convection and large-scale fields is responsible for generating and maintaining this planetary-scale mode (Hayashi and Sumi, 1986).

The wave-CISK (conditional instability of second kind) theory was proposed by Hayashi (1970), in an attempt to parameterize the interaction between convection and large-scale flow. The phase speed of the Kevin wave-CISK is significantly reduced compared to that of the dry wave (Crum and Stevens,

\footnotetext{
${ }^{1}$ Current affiliation: Joint Institute for the Study of the Atmosphere and Oceans, University of Washington, GJ-40, Seattle, WA 98195

(C) 1994, Meteorological Society of Japan
}

1983; Takahashi, 1987; Chang and Lim, 1988), but it is still too fast compared to that of the observed ISO. Furthermore, the linear wave-CISK favors the growth of shortwave. The effect of the surface boundary layer was considered by Wang (1988) but does not improve the deficiency of the linear waveCISK in scale selection (Xie and Kubokawa, 1991). In contrast to the linear theory that allows latent cooling in the descending area, the latent heat released by precipitation in the tropics predominantly occurs in the region of large-scale convergence. Incorporating this conditional heating in an otherwise linear numerical model, Lau and Peng (1987) found a wave-CISK mode with a single convection center and an accompanying wavenumber-one zonal circulation that propagates eastward. They showed that the eastward progagation speed was close to that of the linear Kelvin-wave-CISK. The importance of the conditional heating in generating the wavenumberone wave-CISK mode has been confirmed by many other numerical (Miyahara, 1987; Hendon, 1988; Sui and Lau, 1989; Lim et al., 1990; Yoshizaki, 1991) and two-dimensional analytical (Dunkerton and Crum, 1991; Crum and Dunkerton, 1992) studies. Itoh (1988) reported an exception in a fully nonlinear model. He found that conditional heating was not enough to produce a wavenumber-one structure. It is not clear what has made his results differ from other's.

Analytical theories show that in the absence of dissipation, the most unstable wave-CISK mode 
with conditional heating has infinitesimal ascending area (Kuo, 1961; Yoshizaki and Mori, 1990; Dunkerton and Crum, 1991; Crum and Dunkerton, 1992). In addition to the size of the ascending region, the wave-CISK has another zonal scale, the scale of such fields as zonal wind and geopotential (Fig. 4 shows such an example). ${ }^{2}$ The latter scale is much larger than the former and is inversely proportional to the growth rate. Previous studies have focused on the wavenumber-one mode of wave-CISK. For two convection events that grow rapidly and are separated by a distance much larger than the zonal scale of wave-CISK, however, their interaction would be so weak that they can coexist. Therefore, it is natural to ask the question of whether the wavenumner-one mode is predominant in all circumstances.

It is the purpose of the present study to investigate the condition under which the wavenumberone mode of wave-CISK prevails. we will show that preferred zonal scale of the wave-CISK is highly sensitive to the initial condition and that higher wavenumber modes are also possible. We will use a rotating sphere as our model configuration. A conventional notion is that the Kelvin wave-CISK will be dominant on a rotating sphere or a betaplane. However, we will show that in addition to an eastward propagating mode, a westward propagating one also exists, owing to the large growth rate that diminishes the influence of earth's rotation.

The rest of the paper is organized as following. Section 2 derives the model equations and Section 3 discusses the linear solutions. Section 4 explores the sensitivity of the eastward propagating mode to initial conditions, model resolution and diffusion coefficient. Section 5 describes the westward propagating mode. Finally, results are summarized in Section 6 .

\section{Model equations}

We consider the the infinitesimal amplitude motion driven by cumulus heating. After quadratic nonlinear terms are neglected, the governing equations may be written as

$$
\begin{aligned}
& \frac{\partial \boldsymbol{u}}{\partial t}+f \boldsymbol{k} \times \boldsymbol{u}=-\nabla \varphi \\
& \nabla \cdot \boldsymbol{u}+\frac{\partial \omega}{\partial p}=0 \\
& \frac{\partial}{\partial t} \frac{\partial \varphi}{\partial p}+S^{2} \omega=-\frac{\kappa}{p} Q^{*}
\end{aligned}
$$

in a nondimensional isobaric coordinate

\footnotetext{
${ }^{2}$ This scale will be refered to as the zonal scale of the waveCISK, as the width of ascending motion is known to shrink to the smallest scale. A wave-CISK mode with conditional heating consists of all sinusoidal wavenumbers. Here, the term of zonal wavenumber one will be used in a less strict way to describe a structure with one easterly and one westerly regions along the equator.
}

$$
p=p^{*} / p_{s},
$$

where $p^{*}$ is the dimensional pressure and $p_{s}$ its value at the sea surface. Here, $\nabla$ denotes $\left(\frac{\partial}{\partial x}, \frac{\partial}{\partial y}\right)$, $\boldsymbol{u}=(u, v)$ is the horizontal velocity, $\omega=d p / d t$ is the $p$-velocity, $\varphi$ geopotential, and $Q^{*}$ diabatic heating, $\mathrm{f}$ the Coriolis parameter, $\kappa=R / c_{p}, R$ is the gas constant and $c_{p}$ is the specific heat at constant pressure. The static stability $S^{2}$ is defined as

$$
S^{2}=-R p^{\kappa-1} \cdot \frac{\partial \theta_{0}}{\partial p}
$$

where $\theta_{0}$ is the potential temperature in the basic state.

In most of previous studies, Eq. (2.1)-(2.3) were solved in a vertical finite difference form which introduces numerical errors for low vertical resolutions. Here we adopt the free mode expansion method. In an atmosphere with $S=$ constant, the phase speed of the $j$-th vertical free mode is $C_{j}=\frac{S}{j \pi}$. Using the vertical free modes, we can generally expand model variables into

$$
\begin{aligned}
& \left\{\begin{array}{l}
\boldsymbol{u} \\
\varphi
\end{array}\right\}=\sum_{j=1}^{\infty}\left\{\begin{array}{l}
\boldsymbol{u}_{j}(x, y, t) \\
\varphi_{j}(x, y, t)
\end{array}\right\} \cos (j \pi p), \\
& \omega=-\sum_{j=1}^{\infty} \frac{1}{j \pi} \nabla \cdot \boldsymbol{u}_{j} \sin (j \pi p) .
\end{aligned}
$$

With Eq. $(2.7 \mathrm{c})$, the continuity equation and rigid boundary conditions at $p=0$ and $p=1$ are automatically satisfied. In the absence of heating, $u_{j}$ and $\varphi_{j}$ satisfy shallow water equations with an equivalent depth $\frac{1}{g}\left(\frac{S}{j \pi}\right)^{2}$.

The cumulus heating in an air column is assumed to equal the sum of evaporation from the sea surface and the convergence of the moisture by the horizontal flow, i.e.,

$$
Q^{*}=L(E+D) \frac{f(p)}{\bar{f}} H\left(-\omega_{L}\right),
$$

where $f(p)$ denotes the vertical structure of cumulus heating $Q^{*}, \bar{f}$ is its vertical average,

$$
\begin{aligned}
& E=\frac{\rho_{s} g}{p_{s}} C_{E} \Delta q\left|\boldsymbol{u}_{s}\right| \\
& D=-\int_{0}^{1} q_{0} \nabla \cdot \boldsymbol{u} d p .
\end{aligned}
$$

Here $\rho_{s}$ and $\boldsymbol{u}_{s}$ are the density and wind velocity at the surface, $L$ and $C_{E}$ the latent heat and aerodynamic transfer coefficient, $q_{0}(p)$ and $-\Delta q$ are the mixing ratio in the basic state and its deviation from the saturate value at the surface, respectively. $H\left(-\omega_{L}\right)$ is Heaviside's step function representing conditional heating, 
$H\left(-\omega_{L}\right)= \begin{cases}1, & \text { if }-\omega_{L} \equiv-\left.\omega\right|_{p=p_{L}} \geq 0, \\ 0, & \text { otherwise }\end{cases}$

where $p_{L}$ is a pressure in the lower troposphere and is taken to be $p_{L}=3 / 4$ here. Since the amplitude of the second mode is small for small $f_{2}$, the model results are not sensitive to the value of $p_{L}$ as long as $p_{L}<1 / 2$. Using free vertical modes, we can expand the heating term into

$$
\frac{f(p)}{p}=\sum_{j=1}^{\infty} f_{j} \sin (j \pi p),
$$

where $f_{1} \equiv 1$. For simplicity, we will take into consideration only the first two baroclinic modes and set $f_{j}=0$ for $j \geq 3$. This 2 -mode model is a good approximation of the tropical atmosphere where deep convection and first baroclinic mode are prominent ${ }^{3}$. Substitution of Eq. (2.7), (2.8) and (2.12) in (2.3) yields

$$
\frac{\partial \varphi_{j}}{\partial t}+C_{j}^{2} \nabla \cdot \boldsymbol{u}_{j}=\frac{\kappa L f_{j}}{\pi j \bar{f}}(E+D) H\left(-\omega_{L}\right),
$$

where

$$
\bar{f}=\int_{0}^{1} f(p) d p=\frac{1-f_{2} / 2}{\pi} \equiv \frac{\alpha}{\pi} .
$$

The height of maximum heating increase with $f_{2}$. Here we assume a vertical distribution of water vapor mixing ratio

$$
q_{0}(p)=q_{s} e^{-b(1-p)},
$$

where $q_{s}$ is the value at the surface and $b$ is the scale height of the moisture distribution.

Then Eq. (2.10) gives

$$
D=q_{s} \sum_{j=1}^{2} D_{j} \nabla \cdot \boldsymbol{u}_{j},
$$

where

$$
\begin{aligned}
D_{j} & =-\int_{0}^{1} \frac{q_{0}(p)}{q_{s}} \cos (j \pi p) d p \\
& =-b \frac{(-1)^{j}-e^{-b}}{b^{2}+(j \pi)^{2}} .
\end{aligned}
$$

Choosing a humidity scale $\bar{q}_{s}$ that satisfies

$$
\frac{\kappa L D_{1}}{\alpha} \bar{q}_{s}=C_{1}^{2},
$$

\footnotetext{
${ }^{3}$ Under the assumption of constant static stability, the heating function that excites only the first baroclinic mode has a quite shallow structure in Eq. (2.12). Xie (1991) considered a more realitic static stability profile $S^{2}$ oc $1 / p$ and found that the first baroclinic mode is excited by a deeper heating with the maximum at $p=0.5$. This change in the static stability profile however does not change our results qualitatively.
}

we can normalize surfaace humidity and its deviation from the saturation value as

$$
(q, \Delta q)=\frac{1}{\bar{q}_{s}}\left(q_{s}, \Delta q_{s}\right) .
$$

Although the wind velocity may change in a complicated way across the surface boundary layer, here, we simply assume

$$
\left|\boldsymbol{u}_{s}\right|=\frac{1}{2}|\boldsymbol{u}|_{p=1}=\frac{1}{2}\left|\boldsymbol{u}_{1}-\boldsymbol{u}_{2}\right| .
$$

Substitution of Eq. (2.17)-(2.18) in (2.13) gives

$$
\begin{aligned}
& \frac{\partial \varphi_{j}}{\partial t}+C_{j}^{2} \nabla \cdot u_{j}=C_{1}^{2} \frac{f_{j}}{j} Q \\
& Q=\left[q\left(\nabla \cdot \boldsymbol{u}_{1}-d_{2} \nabla \cdot \boldsymbol{u}_{2}\right)+C_{E}^{\prime} \Delta q\left|\boldsymbol{u}_{1}-\boldsymbol{u}_{2}\right|\right] \\
& \quad \times H\left(\nabla \cdot \boldsymbol{u}_{1}-\nabla \cdot \boldsymbol{u}_{2} / \sqrt{2}\right),
\end{aligned}
$$

where

$$
\begin{aligned}
& d_{2} \equiv-\frac{D_{2}}{D_{1}}=\frac{b^{2}+\pi^{2}}{b^{2}+(2 \pi)^{2}} \frac{1-e^{-b}}{1+e^{-b}}, \\
& C_{E}^{\prime}=\frac{1}{2 D_{1}} \frac{\rho_{s} g}{p_{s}} C_{E} .
\end{aligned}
$$

Note that the cumulus heating in Eq. (2.22) includes two nonlinear terms; conditional heating and the modulus of the wind velocity. This set of nonlinear model equations are homogeneous and their solution is not dependent on the disturbance's amplitude. That is, if $u$ is a solution, so is $A \cdot u$, where $A$ is an arbitrary positive constant. We will call this amplitude-independent model the quasi-linear $(Q L)$ model to distinguish it from the nonlinear model including quadratic nonlinear terms. In such an $Q L$ system, the instability solution with a constant growth rate is possible.

In this paper we will set $C_{E}=0$ and consider the pure wave-CISK case. The heating term then becomes

$$
Q=q\left(\nabla \cdot \boldsymbol{u}_{1}-d_{2} \nabla \cdot \boldsymbol{u}_{2}\right) \cdot H\left(\nabla \cdot \boldsymbol{u}_{1}-\nabla \cdot \boldsymbol{u}_{2} / \sqrt{2}\right)
$$

where conditional heating is the only nonlinear term of the system. The effect of surface evaporation will be discussed briefly at the end of the paper and more extensively in a separate paper (Xie et al., 1993). We here choose the dry phase speed of the first baroclinic mode as $C_{1}=43 \mathrm{~ms}^{-1}$ and values of other parameters as listed in Table 1. Note that the value of $\bar{q}_{s}$ is evaluatd with $f_{2}=0$ but will be used for nonzero value of $f_{2}$, since $f_{2} \ll 1$ in the real atmosphere.

\section{Linear wave-CISK solutions}

Linear wave-CISK theory allows the latent cooling in the descending region and as a result, the Heaviside function in Eq. (2.25) can be dropped. The heating then becomes 
Table 1. Values of parameters

\begin{tabular}{ll}
\hline \multicolumn{1}{c}{ Given } & Calculated \\
\hline$C_{1}-43 \mathrm{~ms}^{-1}$ & $D_{1}=0.16$ \\
$P_{s}=1000 \mathrm{mb}$ & $d_{2}=0.45$ \\
$p_{s}=1.23 \mathrm{kgm}^{-3}$ & $q_{s}=1.7 \times 10^{-2}$ \\
$L=2.5 \times 10^{6} \mathrm{~J} \mathrm{~kg}^{-1}$ & \\
$\kappa=2 / 7$ & \\
$b=4$ & \\
\hline
\end{tabular}

$$
Q=q\left(\nabla \cdot \boldsymbol{u}_{s}-d_{2} \nabla \cdot \boldsymbol{u}_{2}\right)
$$

For an equatorial Kelvin wave on the beta-plane, $v=0$ and

$$
\left\{u_{j}, \varphi_{j}\right\}=\left\{U_{j}, \phi_{j}\right\} e^{i k\left(x-c^{*} t\right)} .
$$

where $k$ is the wavenumber. The dispersion relation can be obtained from Eq. (2.1), (2.21) and (3.1)

$$
c^{4}-\left[(1-q)+\frac{1+F q}{4}\right] c^{2}+\frac{(1-q)+F q}{4}=0
$$

where $F=2 d_{2} f_{2}$ is a measure of heating height and $c=c^{*} / C_{1}$ is the nondimensional phase speed that can be complex. In Eq. (3.3), there are only two independent parameters representing the surface humidity and the partition ratio of heating between the two vertical modes.

The discriminant of Eq. (3.3) for $c^{2}$ is

$$
\Delta=[3-(4+F) q]^{2}-F(4 q)^{2} .
$$

If $\Delta<0, c^{2}$ is complex. Therefore, $c$ will be a conjugate complex with nontrivial real and imaginary parts, i.e., a propagating wave-CISK (P-CISK) occurs. Obviously, the P-CISK occurs only with a deep heating profile $F>0$. The unstable condition for the P-CISK is

$$
q_{c}^{\mathrm{I}} \equiv \frac{3}{(2+\sqrt{F})^{2}}<q<\frac{3}{(2-\sqrt{F})^{2}} \equiv q_{c}^{\mathrm{II}} \text { for } F>0 .
$$

For $F=0, q_{C}^{\mathrm{I}}=q_{c}^{\mathrm{II}}=3 / 4$. With $F=0$, the phase of the first baroclinic mode $c_{1}=\sqrt{1-q}$ is reduced by the moisture effect, while that of the second mode remains unchanged. At $q=3 / 4$, the phase speeds of the two modes become equal. With $F$ increasing from zero, the coalescence of the two baroclinic modes thus first occurs at $q=3 / 4$, leading to the P-CISK.

On the other hand, the boundary curve for the stationary wave-CISK (S-CISK) can be obtained by setting $c=0$ in Eq. (3.3),

$$
q=q_{c}^{\mathrm{III}}(F) \equiv \frac{1}{1-F} .
$$

(F)

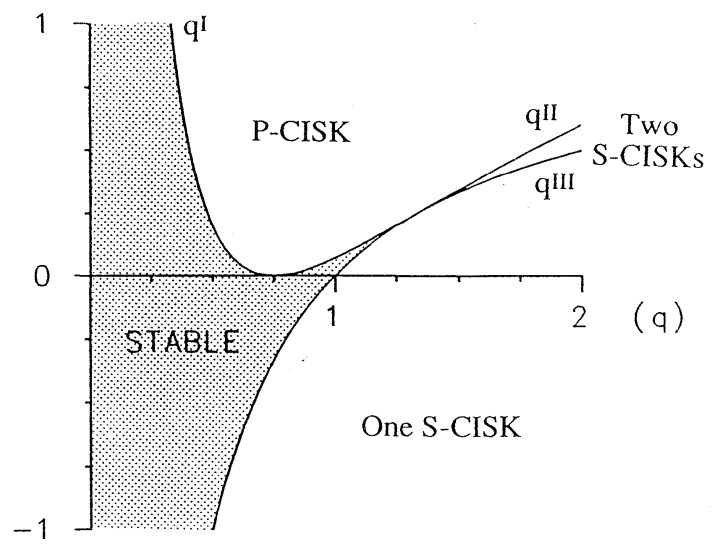

Fig. 1. Schematic diagram of the stability of the two-mode model.

Note that $q_{c}^{\mathrm{III}}(F)$ has a point of contact with $q_{c}^{\mathrm{II}}(F)$ at $F=F_{c}=1 / 4$, i.e., $q_{c}^{\mathrm{III}}\left(\frac{1}{4}\right)=q_{c}^{\mathrm{II}}\left(\frac{1}{4}\right)=\frac{4}{3}$. For $F<$ $F_{c}$, Eq. (3.6) is the neutral curve for the S-CISK.

Figure 1 schematically depicts the boundaries of the two wave-CISK solutions. The $q-F$ plane is divided by $q_{c}^{\mathrm{I}}, q_{c}^{\mathrm{II}}$ and $q_{c}^{\mathrm{III}}$ into four regions; the stable rgion, the P-CISK region, single and two SCISK regions. For $F>F_{c}$, two S-CISKs exist in $q_{c}^{\mathrm{II}}<q<q_{c}^{\mathrm{III}}$, while a single S-CISK occurs in $q>$ $q_{c}^{\text {III }}$. The P-CISK occurs only with deep heating profile and changes into the S-CISK with increasing $q$ for $F>F_{c}$. For $0<F<F_{c}$, on the other hand, a stable region separates the unstable regions of $\mathrm{S}$ and P-CISKs. Similar diagrams for multiple-level models can be found in Chang and Lim (1988) and Yoshizaki (1991).

\section{Eastward propagating modes}

In the following sections, conditional heating is included and the quasi-linear model Eq. (2.1), (2.21) and (2.25) are numerically solved by using the spectral method. Rhomboidal truncation is adopted and the resolution of the model will be represented hereafter by $R k_{m}$ with $k_{m}$ denoting the maximum zonal wavenumber retained. Detailed description of the spectral method can be found in Bourke (1988). Second-order horizontal diffusion term is added to each time-evolving equation. A semi-implicit timedifference scheme is employed, which slows down the phase speed of the short gravity wave and ensures the stable computation. Because the small-scale motion is expected to be important in a wave-CISK model, the time step is chosen carefully, being 60 , 30, 15 and 12 minutes in R31, R63, R127 and R159 versions of the model, respectively. Smaller time step does not yield qualitative change in results. We choose $q=0.75$ or $q^{*}=1.275 \times 10^{-2}$ in dimension, and $f_{2}=0.2$ that corresponds to a heating profile with a maximum at $p=0.55$. With these parame- 


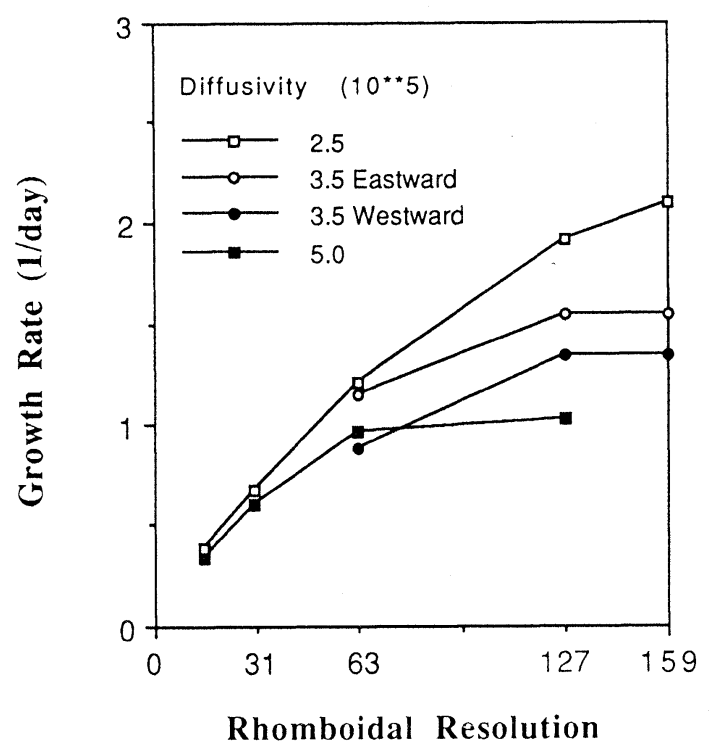

Fig. 2. Growth rate of wave-CISK as a function of model resolution.

ters the nondimensional complex phase speed of the linear P-CISK is $c=0.53+0.15 i$ according to Eq. (3.6). The corresponding dimensional period is then 20 days for the wavenumber-one mode.

The inviscid wave-CISK favors the modes with small ascending area. In a numerical model the smallest spatial scale is limited by the horizontal resolution. As a result, the growth rate and the zonal structure of the numerical solution are sensitive to model resolution, unless the resolution is fine enough to resolve the scale at which the diffusion comes into effect (Crum and Dunkerton, 1992). We have performed a series of experiments, changing both horizontal resolution and diffusivity. Figure 2 shows the growth rate of the model solution as a function of resolution. The growth rate generally increases with the resolution, due to the decrease in the width of ascending motion. However, the numerical solution seems to converge to the true solution at a resolution that depends on the diffusivity. For example, the growth rate levels off at R63 for a diffusivity of $5 \times 10^{5} \mathrm{~m}^{2} \mathrm{~s}^{-1}$. Further increase in resolution does not change the growth rate and spatial structures of the solution. The growth rate is also sensitive to diffusivity; the smaller the diffusivity, the larger the growth rate is for a fixed resolution. Hereafter, we will concentrate on the results from experiments with a diffusivity of $3.5 \times 10^{5} \mathrm{~m}^{2} \mathrm{~s}^{-1}$, which is in a widely accepted range. For this value of diffusivity, the numerical solution converges to the true solution at $\mathrm{R} 127$. The e-folding time of the growth rate of the converged solution is 0.65 day. This value of growth rate is comparable to those in Lim et al. (1990) and Crum and Dunkerton (1992). In the following, results are shown from the R159 model.
If initilizing the calculation with an eastwardmoving disturbance that has a single ascending branch in the zonal direction, we obtain an eastward propagating instability mode. Its phase speed is close to that of the linear P-CISK. In this paper we will concentrate on the horizontal structures of wave-CISK. Its vertical structure has been discussed in Lau and Peng (1987), Lim et al. (1990) among others. Since $f_{2}$ and the amplitude of second baroclinic mode are small, we will only show the flow pattern of the first baroclinic mode for simplicity. The second mode has a much smaller zonal scale and the zonal scale of a wave-CISK mode is thus determined by that of the first. Figure 3 shows the horizontal structures of the instability mode. The heating is confined to a narrow zonal extent and is equatorially trapped. The flow field resembles that of Gill's pattern (Gill, 1980). to the east of the ascending region, the Kelvin wave response is dominant and the flow is nearly zonal. To the west there are substantial merdional flows and the response resembles Rossby waves. These modal structures are similar to those obtained by Lau and Peng (1987) and many others.

For a disturbance that propagates and grows at constant rates and with an unchanged spatial structure, the model variables may be expressed as

$$
\begin{aligned}
& \left\{\boldsymbol{u}_{j}, \varphi_{j}, Q\right\} \\
& \quad=\left\{\boldsymbol{U}_{j}(X, y), \Phi_{j}(X, y), Q^{*}(X, y)\right\} \cdot \exp (\sigma t),
\end{aligned}
$$

where $X=x-c_{r} t, c_{r}$ is the phase speed and $\sigma$ the growth rate. Substitution of Eq. (4.1) in (2.1) and (2.21) yields

$$
\begin{aligned}
& -c_{r} \frac{\partial \boldsymbol{U}_{j}}{\partial X}+f \boldsymbol{k} \times \boldsymbol{U}_{j}=-\nabla \Phi_{j}-\sigma \boldsymbol{U}_{j}, \\
& -c_{r} \frac{\partial \Phi_{j}}{\partial X}+C_{j}^{2} \nabla \cdot \boldsymbol{U}_{j}=C_{1}^{2} \frac{f_{j}}{j} Q^{*}-\sigma \Phi_{j} .
\end{aligned}
$$

In other words, the spatial structure of the instability can be reproduced by solving a steady response problem in which the heating moves at the phase speed of the instability and the damping rate is equal to the growth rate. Under the longwave approximation, the amplitude of the response decreases exponentially away from the heating with an $e$-folding scale proportional to $1 / \sigma$ (Yamagata, 1987). As seen in Fig. 3, the convergence near the equator is mainly caused by the zonal wind. Therefore, the radius for an isolated convection event to influence other such events may be defined as the zonal scale of the zonal wind field, which is inversely proportional to the growth rate.

Figure 4 provides a close look at the zonal structures of the instability at the equator. There is only one ascending areaa along the equator and the easterlies and westerlies occupy the regions east and west of the heating respectively. In contrast to the 


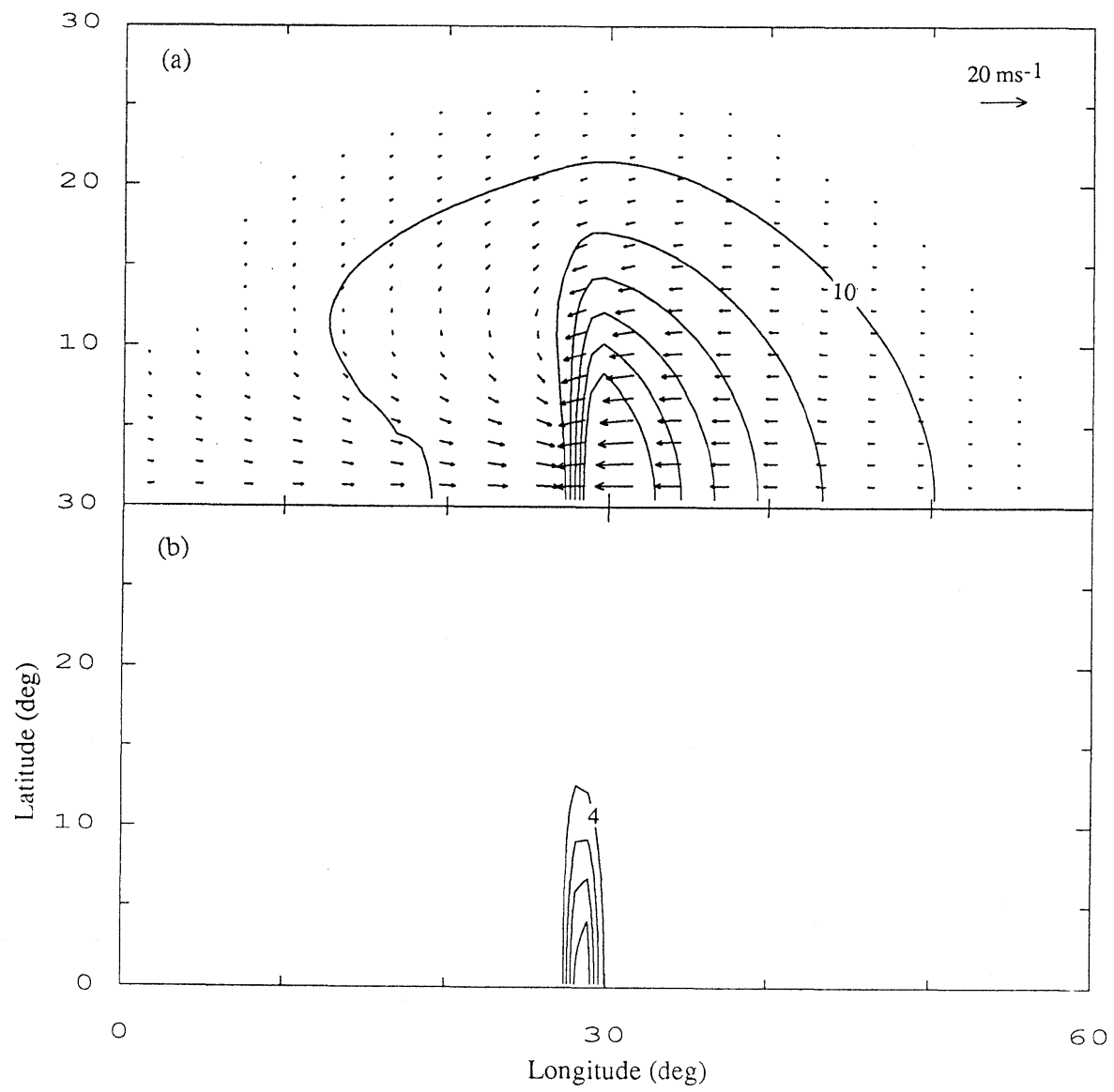

Fig. 3. Horizontal structures of the wavenumber-one eastward-moving mode in an R159 model: a) geopotential height (contour interval: $10 \mathrm{~m}$ ) and wind velocity vectors, and b) latent heating rate (contour interval: $\left.4 \times 10^{-4} \mathrm{~s}^{-1}\right)$. Only the first baroclinic components $\left(-\varphi_{1} / g\right.$ and $\left.-u_{1}\right)$ are shown in a) for both the amplitude and zonal scale of the second mode are smaller.

propagating mode in a non-rotating system (Lim et al., 1990; Crum and Dunkerton, 1992), the $e$-folding scales of the zonal wind are comparable on the two sides of the heating. This is because the Dopplershifted phase speed of the gravest Rossby wave is nearly equal to that of the Kelvin wave in a coordinate moving eastward at the phase speed of the instability. The maximum easterly at the eastern edge of the heating is greater than the maximum westerly at the western edge, a characteristic of the response to an eastward moving heat source.

The influence radius of a convection event may be estimated as the average of the $e$-folding lengths of the Kelvin and Rossby responses, $\lambda_{r}=\frac{2}{3} \cdot \frac{c}{\sigma}=34^{\circ}$ longitudes. Consistent with this estimate, the significantly non-zero zonal winds in Fig. 4 are confined to only one-fourth of the whole equatorial belt. This makes one wonder what happens if we put another convection event in. We take an instantaneous field from the previous experiemnt, shift it eastward for a distance $\lambda_{d}$ and then add it onto the orginal field. With such initial conditions, we can then investigate the interaction between the two convection events.



Fig. 4. Heating rate (unit: $2 \times 10^{-3} \mathrm{~s}^{-1}$ ) and zonal wind velocity (unit: $20 \mathrm{~ms}^{-1}$ ) on the equator as functions of longitude.

The fate of these two convection events is shown in Fig. 5, where the horizontal coordinate moves eastward at the phase speed of wave-CISK. With the two convection centers close to each other $\left(\lambda_{d}=\right.$ $45^{\circ}$ ) so that the distance between them is smaller than the twice of the influence radius, strong interaction occurs and one of them dies out after day 200. When separated far enough $\left(\lambda_{d}=135^{\circ}\right)$, on the other hand, two convection events only interact weakly and coexist in the 600-day integration without losing each other. Although the amplitude ratio 




Fig. 5. Time-longitude sections of latent heating rate along the equator in a coordinate moving eastward at a speed of $24 \mathrm{~ms}^{-1}$ for runs with two convection cores that are initially a) closely located and b) far apart. The heating rate is normalized with its maximum at each time step. Contour interval is 0.4 and zero contour is omitted. The left panels depict the amplitude ratio $Q_{2} / Q_{1}$ as a function of time, where $Q_{1}$ is the amplitude of the convection event at $180^{\circ}$ and $Q_{2}$ is that to the east. The highfrequency oscillation in the left panels is due to sampling at fixed grid points.

between the two convection events varies in this initial value problem, it approach one at the end of the integration.

We then go further to investigate the model evolution from a more zonally homogeneous initial condition of a wavenumber-15 dry sinusoidal Kelvin wave $^{4}$. Figure 6 depicts the time-longitude section of convective heating on an eastward-moving zonal coordinate. After a few days adjustment, the dry Kelvin wave emerges as a wavenumber 15 mode of wave-CISK with 15 convection events of equal amplitude and interval. This configuration of convection is however unstable to small round-off errors. See Appendix for more discussion on the stability of wave-CISK solutions. Consolidation occurs among convection centres after the first 30 days. Finally, the state of four convection events emerges

\footnotetext{
${ }^{4} \mathrm{~A}$ similar multi-center solution is obtained from an experiment initilized with Kelvin waves that have the same amplitude but have a random phase distribution in the sinesoidal wavenumber space.
}

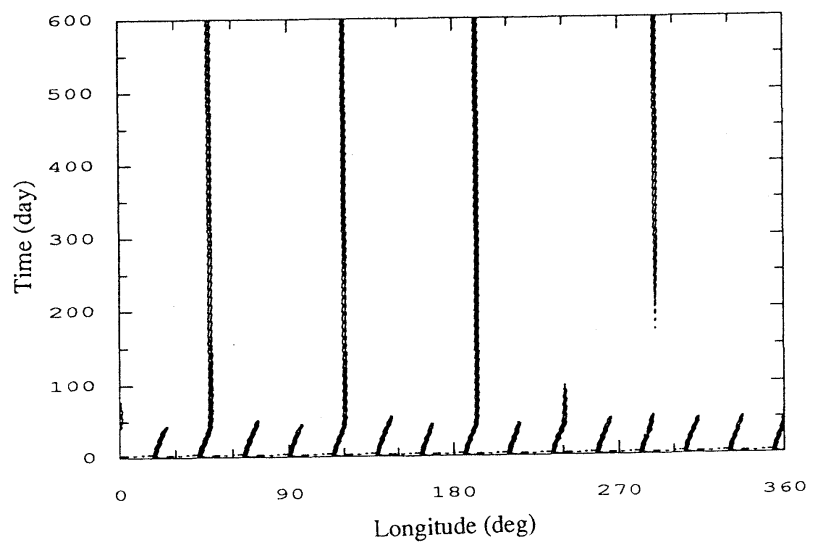

Fig. 6. Same as Fig. 5 but for the run with a wavenumber-15 initial condition. The calculation is performed for 850 days and only the results for the first 600 days are depicted.

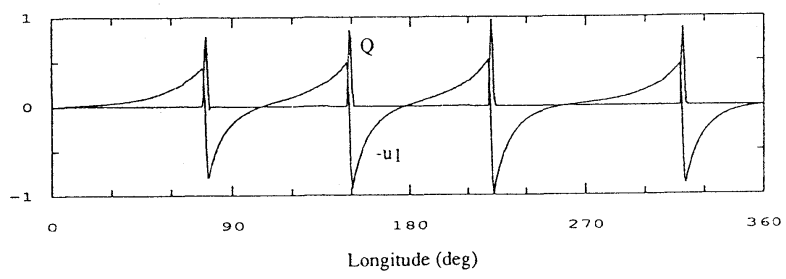

Fig. 7. Same as Fig. 4 but on day 500 of the run with a wavenumber-15 initial condition.

and prevails throughout the rest of the 850-day integration. Figure 7 show the zonal structure of the model solution on day 500. The four events have nearly the same amplitude and are separated from each other at nearly but not exactly the same distance. The zonal wind structure associated with each convection event looks very similar to that of the wavenumber-one mode and is affected little by the other events. This is also reflected in the growth rate, which after the initial consolidation of convection cores, is almost the same as that of the wavenumber-one mode (see also Table 2).

The maximum number of convection centers is presumably determined by the zonal scale of a single center. As seen in Fig. 2, a larger diffusivity leads to a reduction in the growth rate and thus to a larger zonal scale. This increases the influence radius of a convection event and decreased the number of convection events that can be contained in the global domain. We observed a maximum of two convection events in the calculations with of $A=5 \times 10^{5} \mathrm{~m}^{2} \mathrm{~s}^{-1}$. On the other hand, smaller diffusivity increases the growth rate and decreases the influence radius. This allows a larger number of convection centers. Indeed, the states of five non- 
identical convection events for $A=2.5 \times 10^{5} \mathrm{~m}^{2} \mathrm{~s}^{-1}$ and twelve for $A=10^{5} \mathrm{~m}^{2} \mathrm{~s}^{-1}$ were found stable, although these two solutions may not yet be converged at the $\mathrm{R} 159$ resolution. These experiments consistently indicate that two or more convection events can coexist, behaving quite independently of each other, once their growth rate is great enough to make their zonal radius of influence smaller than one-half of earth's circumference at the equator.

Lim et al. (1990) reported a different multicell CISK solution in a 2-dimensional model. They found that multiple convection centers were grouped together within a small zonal extent but a grossly wavenumber-one east-west circulation was still prevalent. In contrast, the multiple convection events here are separated far apart compared to their influence radius and basically independent of each other. As a result, the flow field is dominated by high wavenumber structures. The wave-CISK mechanism does not always select the wavenumberone mode in this noise-free (except numerical roundoff errors) system, and seems even less likely to do so in the noise-abundant real atmosphere.

One might have noticed that the meridional scale of wave-CISK in Fig. 3 is much smaller than 90 degree latitudes. One might expect multiple convection events to occur in the meridional direction, too. We have performed experiments with initial disturbances in the extratropics. In one of such experiments, two localized eastward-moving heatings are initially introduced in an equatorially symmetric hemispheric model; one centered around the equator and the other around $45^{\circ}$. Because the earth's rotation is still felt by wave-CISK with a growth rate of $(0.65 \mathrm{day})^{-1}$, the equatorial disturbance grows much faster than the extratropical one and eventually overwhelms the latter. If only the extratropical heating is introduced initially, the associated disturbances propagrate toward the equator and the equatorial disturbances then become dominant. Therefore, the wave-CISK seems to prefer the equatorial distrubance, at least in the case with a finite diffusivity.

\section{Westward propagating mode}

Most of the previous studies have focused on the eastward-propagating waave-CISK modes, assuming that the Kelvin wave-CISK has the largest growth rate and will dominate. With a large damping or slow rotation rate in a linear model, Matsuda and Kato (1987) showed that the tropical response to an isolated heating is dominated by gravity waves. This implies that the large growth rate associated with the wave-CISK tends to diminish the difference between the east and west directions. The westwardpropagating mode might also be possible, provided that the growth rate of wave-CISK is large enough.

To obtain the westward-propagating mode, we first turn the interactive heating off and force the model for 5 days with a prescribed heating that is equatorially trapped and moves westward. A damping rate of $(0.5 \text { day })^{-1}$ is used. The interactive heating then is turned on and the model is allowed to evolve freely. A westward propagating mode indeed occurs, whose phase speed is almost the same as that of the eastward propagating one. As seen from Fig. 2 , the numerical solution also converges at R127. The converged solution has a growth rate of $(0.75$ day $)^{-1}$, which is slightly smaller than that of the eastward-propagating one.

Figure 8 shows the spatial structures of the westward-moving mode. The heating distribution is very similar to that of the eastward-moving one but the flow field is not. Since the mode moves at the speed one half of the dry phase speed of the first baroclinic Kelvin wave, only the gravity waves can propagates to the west of the heating. As a result, the cross-isobar flow is dominant there. To the east of heating, the flow field consists of all possible waves including Rossby, Kevin and gravity waves. Quasigeostrophic flow can be seen in the off-equatorial region east of the heating. Far east of the heating, the response seems dominated by Kelvin and gravity waves. In terms of the spatial stucture, the eastward and westward propagating modes are very different, with the former's flow field dominated by the Rossby and Kevin wave responses and the latter's by the gravity wave response. For modes with higher growth rates, however, this difference is expected to become smaller. In the limit of infinite rawth rate, the difference bewteen the eastward and westward moving modes should vanish.

\section{Discussion}

The behavior and zonal structures of the waveCISK with conditional heating have been investigated on a rotating sphere. We have used fine enough horizontal resolution to ensure that our numerical solutions are not sensitive to the model resolution and converge to the true solutions. An eastward-moving mode with a single ascending area is obtained in the model, as in the 2-D model of Crum and Dunkerton (1992). This wavenumberone mode is obtained with an initial condition that contains only one convection event. With more general initial conditions, however, modes with more than one convection events develop in the same model. We have studied the interaction between two convection events and found that they coexist and affect each other little if they are separated by a distance larger than the twice of the convection's influcence radius. In addition to the eastward-propagating mode, we have also found a westward-propagating mode. Unlike their counterparts in the 2-dimension non-rotating system, the two modes that propagate in the opposite directions 


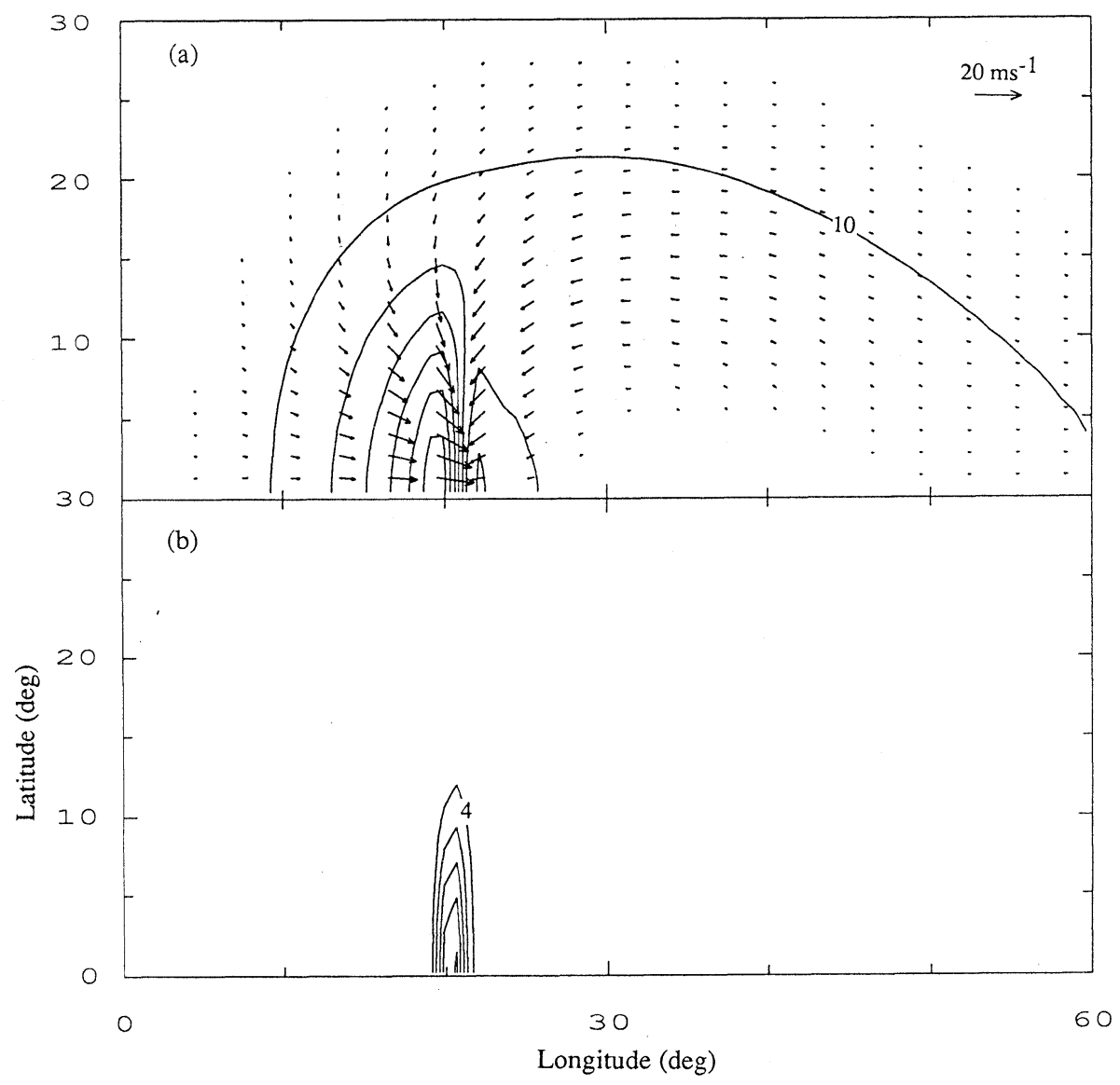

Fig. 8. Same as Fig. 3 but for the westward-moving mode.

have very different spatial structures. The flow field of the eastward-propagating mode is dominated by the Rossby-Kelvin wave response as in Gill (1980), while the westward-propagating one consists of all Rossby, Kelvin and gravity waves.

Both the observations and GCM experiments suggest that the atmosphere tend to select the wavenumber-one mode for moist convective motion. The present study suggests that the wave-CISK do not always select the wavenumber-one mode and that the number of convection events with nearly equal amplitude be sensitive to the initial condition. In the real atmosphere there are plenty of independent, small-scale disturbances, making it even harder for wave-CISK to select the wavenumber-one mode. This may explain why conditional heating was insufficient to maintain a wavenumber-one mode in Itoh (1988)'s experiments with a fully nonlinear wave-CISK model.

In a quasi-linear system, the zonal scale of waveCISK is inversely proportional to the growth rate. If the growth rate is low and hence the influence radius of wave-CISK is comparable or larger than the equatorial circumference of the earth, only the wavenumber one mode can exist in a numerical model for a long time. As the growth rate increases, the zonal scale of the mode decreases. If the growth rate is large enough, the influence radius of wave-CISK can be much smaller than the earth's circumference. In this high growth regime, the interaction is weak between two convection events that are apart far enough. As a consequence, the growth rate difference is very small among the lowest wavenumber modes, as demonstrated in Table 2. High growth rate is a necessary condition for high wavenumber modes. In the high growth regime, whether the wavenumber one mode or a higher wavenumber modes will be dominant depends on the initial conditons. In a numerical model, the zonal stuctures of wave-CISK is sensitive to the growth rate in general, but also to the initial conditions if the growth rate is high. As for the growth rate, it is sensitive to such parameters as the surface humidity, heating height and diffusivity. Therefore, in order to obtain a wavenumber one wave-CISK mode independent of initial conditions, it is important to choose these parameters and let the growth rate to be not too large. Non-rotating, two-dimensional wave-CISK models have been proven to be a very useful tool (e.g. Crum and Dunkerton, 1992), but previous numerical studies with these models have focused only on the wavenumber one mode. In a rotating sys- 


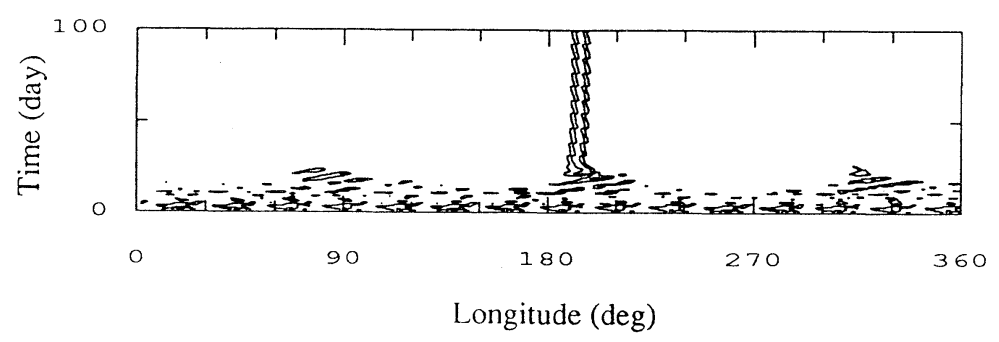

Fig. 9. Time-longitude section of latent heating rate along the equator in a coordinate moving eastward at a speed of $21.4 \mathrm{~ms}^{-1}$ in an R63 model including surface evaporation. Parameters used: $f_{2}=0, q=0.75$ (stable to the wave-CISK) and $\Delta q=0.2$. The initial condition is a wavenumber-15 dry Kelvin wave, the same as that in Fig. 6.

tem the zonal scale of a wave-CISK mode, with the Rossby wave response to the west of the convection and the Kelvin response to the east, is only $2 / 3$ of that in a non-rotating sytem. In this sense, waveCISK is more likely to develop high wavenumber modes in a rotating system. Except this, the above conclusions seem not to be dependent on the earth's rotation. It would be interesting to investigate the sensitivity of these two-dimensional models to initial conditions in the high growth regime.

Recent soundings suggest that the stratification of the tropical atmosphere be marginally stable in the time-mean sense (Xu and Emanuel, 1989). In an atmosphere stable to wave-CISK, the evaporationwind feedback (EWFB) destablizes the Kelvin wave (Emanuel, 1987; Neelin et al., 1987). When surface evaporation is turned on $\left(C_{E}^{\prime} \neq 0\right)$, Eqs. (2.1) and (2.21)-(2.22) have a quasi-linear EWFB instability solution (Xie et al., 1993). Figure 9 shows the evolution of such an EWFB mode from the same wavenumber-15 initial condition as in Fig. 6 . In the case of wave-CISK, multiple convection events exist with little interaction among themselves. In contrast, a wavenumber-one mode of the EWFB instability, with a single major convection core, emerges rapidly within a matter of 30 days and prevails. The evaporation-wind feedback, with the help of conditional heating, seems very efficient in selecting the wavenumber-one mode for the covective motion. ${ }^{5}$

There are several unrealistic treatments in the formulation of the present wave-CISK model, which is commonly used though. First, an infinite moisture supply is assumed, whereas the moisture distribution in the real atmosphere is affected both by surface evaporation and vertical advection. A fully interactive moisture budget consideration is desirable. As a first step, inclusion of evaporation effect has led to a more robust selection of the wavenumber-one mode as seen in Fig. 9. Second, the heating profile is specified a priori, which could change both in

\footnotetext{
${ }^{5}$ Another distinction from wave-CISK is that the phase speed, growth rate and spatial structures of the quasi-linear EWFB mode are insensitive to the horizontal resolution. An R15 model can give a quite good result.
}

Table 2. Difference in the growth rate between the wavenumber one and $K$ modes.

\begin{tabular}{cccccc}
\hline$K$ & 1 & 2 & 4 & 10 & 15 \\
\hline$\frac{\sigma_{1}-\sigma_{K}}{\sigma_{1}}(\%)$ & 0.0 & 0.0 & 0.0 & 0.8 & 3.6 \\
\hline
\end{tabular}

space and time. Third, quadratic nonlinear terms are neglected in the momentum and temperature equations, which is important in limiting the unstable growth and defining the convective motion at finite amplitudes. A common problem with all quasi-linear modes is that the convection occurs in a relatively small area and is persistent with an infinite life time. In the reality, the convection has a hierarchy of temporal and spatial strutures, from individual tropical storm, clould cluster to super cloud cluster (Nakazawa, 1988). To understand the interaction among convective motions on various scales, more observational and theoretical work is needed.

\section{Acknowledgements}

It is my pleasure to acknowledge Drs. A. Kubokawa, Y. Hayashi and K. Hanawa for their invaluable discussions and advice. I also had useful discussions with Drs. Y.-Y. Hayashi, I. Held, K. Nakajima and A. Numaguti. Comments by Dr. S. Miyashara and anonymous reviewers are very helpful in improving the manuscript. Part of the work was performed at Tohoku University, Japan. This study is funded by a grant from the National Oceanic and Atmospheric Administration (NA26G0102-01). The views expressed herein are those of the author and do not necessarily reflect the views of NOAA or any of its agencies.

\section{Appendix}

\section{Modes with multiple identical convection centers}

We can obtain the wavenumber $K$ solution by dividing the globe into $K$ spherical triangles that have the same size and are zonally cyclic. In such a spherical triangle, the lowest wavenumber other than zero 
is $K$. Table 2 gives the growth rate difference from the $K=1$ mode. The growth rate increases as $K$ decreases if $K$ is not small. This, consistent with previous analytical theory (Kuo, 1961; Dunkerton and Crum, 1991; Crum and Dunkerton, 1992), indicates that the interaction among the convection events becomes weak when they are apart. When $K$ is small so that the zonal size of the spherical triangle is comparable to or large than the twice of the influence radius of a convection event, the interaction becomes so weak that there is no measurable difference in the growth rate for $K \leq 4$.

We can add local time derivative terms in Eqs. (4.2) and (4.3) to construct equations for slow variations. The wavenumber $K$ mode, for any $K$, is a steady solution to the model so obtained, as demonstrated analytically by Crum and Dunkerton. It is not clear from the analytical theory, however, whether these steady solutions are stable in the global domain. The numerical experiment illustrated in Fig. 6 shows that the $K=15$ mode is unstable to small amplitude disturbances and evolves into a lower wavenumber mode. The decrease in the number of convection events stops presumabley when the distance between them becomes smaller than the twice of the influence radius. Consistent with Fig. 6 , the $K=4$ solution, with four identical convection events, was found to be stable in a global domain experiment and showed no changes in its spatial sturctures.

\section{References}

Bourke, W., 1988: Spectral methods in global climate and prediction models. In "Physically-based modeling and simulation of climate and climatic change (Part1)". M.E. Schlesinger, Ed., Kluwer Academic Publisher, 169-222.

Chang, CP. and H. Lim, 1988: Kelvin-wave CISK: a possible mechanism for the 20-50 day oscillation. $J$. Atmos. Sci., 45, 1709-1720.

Crum, F.X. and T.J. Dunkerton, 1992: Analytical and numerical models of wave-CISK with conditional heating. J. Atmos. Sci., 49, 1693-1708.

Crum, F.X. and D.E. Stevens, 1983: A comparison of two cumulus parametrization schemes in a linear model of wave-CISK. J. Atoms. Sci., 40, 2671-2688.

Dunkerton, T.J. and F.X. Crum, 1991: Scale selection and propagation of wave-CISK with conditional heating. J. Meteor. Soc. Japan, 69, 449-457.

Emanuel, K.A., 1987: An air-sea interaction model of intraseasonal oscillations in the tropics. J. Atoms. Sci., 44, 2324-2340.

Gill, A.E., 1980: Some simple solutions for heat-induced tropical circulation. Quart. J. Roy. Meteor. Soc., 106, 447-462.

Hayashi, Y., 1970: A theory of large-scale equatorial waves generated by condensation heat and accelerating the zonal wind. J. Meteor. Soc. Japan, 48, 140-160.
Hayashi, Y. and D.G. Golder, 1986: Tropical intraseasonal oscillations appearing in a GFDL general circulation model and FGGE data, Part I: Phase propagation. J. Atoms. Sci., 43, 3058-3067.

Hayashi, Y. and D.G. Golder, 1988: Tropical intraseasonal oscillations appearing in a GFDL general circulation model and FGGE data, Part II: Structure. J. Atoms. Sci., 45, 3017-3033.

Hayashi, Y.Y. and A. Sumi, 1986: The 30-40 day oscillations simulated in an "Aqua Planet" model. $J$. Meteor. Soc. Japan, 64, 451-467.

Hendon, H.H., 1988: A simple model of the 40-50 day oscillation. J. Atoms. Sci., 45, 569-584.

Itoh, H., 1988: The mechanism for the scale selection of tropical intraseasonal oscillations. Part I: Selection of wavenumber- 1 and the three-scale structure. $J$. Atoms. Sci., 46, 1779-1798.

Kuo, H.-L., 1961: Convection in conditionally unstable atmosphere. Tellus, 13, 441-433.

Lau, K.M. and L. Peng, 1987: Origin of low-frequency (intraseasonal) oscillations in the tropical atmosphere. Part I: Basic theory. J. Atoms. Sci., 44, 950-972.

Lau, N.-C. and K.M. Lau, 1986: The structure and propagation of intraseasonal oscillations appearing in a GFDL GCM. J. Atoms. Sci., 43, 2023-2047.

Lau, N.-C., I.M. Held and J.D. Neelin, 1988: The Madden-Julian oscillation in an idealized general circulation model. J. Atmos. Sci., 45, 3810-3832.

Lim, H., T.-K. Lim and C.-P. Chang, 1990: Reexamination of wave-CISK theory: Existence and properties of nonlinear wave-CISK modes. J. Atmos. Sci., 47, 3078-3091.

Madden, R.A. and P.R. Julian, 1972: Description of global-scale circulation cells in the tropics with a 40 50 day period. J. Atoms. Sci., 29, 1109-1123.

Matsuda, Y. and T. Kato, 1987: The linear response of a global atmosphere to tropical heating-Effect of planetary rotation. J. Meteor. Soc. Japan, 65, 819842.

Miyahara, S., 1987: A simple model of the tropical intraseasonal oscillations. J. Meteor. Soc. Japan, 65, 341-351.

Nakazawa, T., 1988: Tropical super clusters within intraseasonal variations over the western Pacific. $J$. Meteor. Soc. Japan, 66, 823-839.

Neelin, J.D. and I.M. Held and K.H. Cook, 1987: Evaporation-wind feedback and low-frequency variability in the tropical atmosphere. J. Atoms. Sci., 44, 2341-2348.

Sui, C.H. and K.M. Lau, 1989: Origin of low-frequency (intraseasonal) oscillations in the tropical atmosphere. Part I: Effect of an improved treatment of moist processes. J. Atmos. Sci., 46, 37-56.

Swinbank, R., T.N. Palmer and M.K. Davey, 1988: Numerical simulations of the Madden-Julian oscillations. J. Atmos. Sci., 45, 774-788.

Tokioka, T., K. Yamazaki, A. Kitoh and T. Ose, 1988: The equatorial 30-60 day oscillaiton and the Arakawa-Schubert penetrative cumulus parameterization. J. Meteor. Soc. Japan, 66, 883-901.

Takahashi, K., 1987: A theory of the slow phase speed of the intraseasonal oscillation using the wave-CISK. 
J. Meteor. Soc. Japan, 65, 43-49.

Wang, B., 1988: Dynamics of the tropical low-frequency waves: An analysis of the moist Kelvin wave. $J$. Atmos. Sci., 45, 2051-2065.

Xie, S.-P., 1991: Evaporation-wind feedback and the organizaing of tropical convection on the planetary scale: A theory of tropical intraseasonal oscillations. Ph. D. Thesis, Tohoku University, Japan, 133 pp. +62 figs.

Xie, S.-P. and A. Kubokawa, 1990: On the wave-CISK in the presence of a frictional boundary layer. $J$. Meteor. Soc. Japan, 68, 651-657.

Xie, S.-P., A. Kunokawa and K. Hanawa, 1993: Evaporation-wind feedback and the organizing of tropical convection on the planetary scale. Part I:
Quasi-linear instability. J. Atmos. Sci., 50, 38733883.

Xu, K.-M. and K.A. Emanuel, 1989: Is the tropical atmosphere conditionally unstable? Mon. Wea. Rev., 117, 1471-1479.

Yamasaki, M., 1972: Small-amplitude convection in a conditionally unstable stratification. J. Meteor. Soc. Japan, 50, 465-481.

Yashizaki, M., 1991: Selective amplification of the eastward-propagating mode in a positive-only waveCISK model on an equatorial beta plane. J. Meteor. Soc. Japan, 69, 353-373.

Yoshizaki, M. and A. Mori, 1990: Another approach on linear theory of conditionally unstable convection: A forcing problem. J. Meteor. Soc. Japan, 68, 327-333.

\title{
正の加熱だけを課した Wave-CISK の東西スケールの選択について
}

\author{
謝 尚平 ${ }^{1}$ \\ (米国プリンストン大学)
}

正の加熱だけを用いた場合の wave-CISK を全球スペクトルモデルを用いて調べた。ある特定の初期条件 から計算した場合、上昇領域が 1 カ所だけの東進する波数 1 の不安定モードが得られた。しかし、一般的 な初期条件から始めた場合は、ほぼ同じ振幅を持ち、赤道上で東西方向にほぼ等間隔に分布する複数の対 流モードが現れる。一つの対流が他の対流に影響し得る距離は成長率に反比例するので、早く成長する対 流の影響半径が地球の周長よりもずっと小さい場合に、このような高波数モードが存在し得る。東進する 不安定モードのほかに、積雲加熱に対する重力波応答が卓越する流れの構造を持つ西進不安定モードも検 出された。

これらの結果は、正の加熱だけの wave-CISK は必ずしも波数 1 の東進モードを選択しないことを示唆す る。東西スケールの選択性を持つ新たな機構も提案した。 